\title{
The use of nocturnal flights for barrier crossing in a diurnally migrating songbird
}

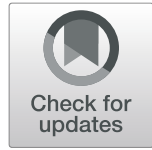

\author{
Christie D. Lavallée ${ }^{1}$, Saeedeh Bani Assadi ${ }^{1}$, Alicia M. Korpach', James D. Ray², Jason D. Fischer ${ }^{3}$, Joe Siegrist ${ }^{4}$ and
} Kevin C. Fraser ${ }^{1 *}$ (D)

\begin{abstract}
Background: The migration patterns of land birds can generally be divided into those species that migrate principally during the day and those that migrate during the night. Some species may show individual plasticity in the use of day or night flight, particularly when crossing large, open-water or desert barriers. However, individual plasticity in circadian patterns of migratory flights in diurnally migrating songbirds has never been investigated.

Methods: We used high precision GPS tracking of a diurnal, migratory swallow, the purple martin (Progne subis), to determine whether individuals were flexible in their spring migration strategies to include some night flight, particularly at barrier crossing.

Results: Most (91\%) of individuals made large (sometimes $>1000 \mathrm{~km}$ ), open-water crossings of the Caribbean Sea and the Gulf of Mexico that included the use of night flight. 32\% of all water crossings were initiated at night, demonstrating that night flight is not only used to complete large crossings but may confer other advantages for diurnal birds. Birds were not more likely to initiate crossings with supportive winds, however crossings were more likely when they reduced travel distances. Our results are consistent with diurnal birds using night flight to help achieve time- and energy-savings through 'short cuts' at barrier crossings, at times and locations when foraging opportunities are not available.

Conclusions: Overall, our results demonstrate the use of nocturnal flight and a high degree of individual plasticity in migration strategies on a circadian scale in a species generally considered to be a diurnal migrant. Nocturnal flights at barrier crossing may provide time and energy savings where foraging opportunities are low in an otherwise diurnal strategy. Future research should target how diel foraging and refueling strategies support nocturnal flights and barrier crossing in this and other diurnal species.
\end{abstract}

Keywords: Circadian timing, Aerial insectivores, GPS tracking, Individual plasticity, Ecological barrier, Fly-and-forage migration, Diurnal migrant

\section{Background}

The migratory movements of animals can often be characterized by whether they occur primarily during daylight hours or during the night. Many diurnal land bird species that are usually active only during the day,

\footnotetext{
* Correspondence: kevin.fraser@umanitoba.ca

'Department of Biological Sciences, University of Manitoba, Winnipeg, MB, Canada

Full list of author information is available at the end of the article
}

migrate during the night. This can confer advantages of time and energy savings, and can reduce predation risk $[1,2]$. However, these mainly nocturnal migrants can also sometimes be observed moving in a migratory direction during the day [1], demonstrating some flexibility in circadian timing strategies. In many cases, these movements can be attributed to completing the crossing of a major ecological barrier, to re-orientate and correct movement errors, or to avoid poor weather [1,3-5]. For

\section{$\triangle B M C$}

(c) The Author(s). 2021 Open Access This article is licensed under a Creative Commons Attribution 4.0 International License, which permits use, sharing, adaptation, distribution and reproduction in any medium or format, as long as you give appropriate credit to the original author(s) and the source, provide a link to the Creative Commons licence, and indicate if changes were made. The images or other third party material in this article are included in the article's Creative Commons licence, unless indicated otherwise in a credit line to the material. If material is not included in the article's Creative Commons licence and your intended use is not permitted by statutory regulation or exceeds the permitted use, you will need to obtain permission directly from the copyright holder. To view a copy of this licence, visit http://creativecommons.org/licenses/by/4.0/ The Creative Commons Public Domain Dedication waiver (http://creativecommons.org/publicdomain/zero/1.0/) applies to the data made available in this article, unless otherwise stated in a credit line to the data. 
example, recent tracking data has shown that nocturnally migrating songbirds crossing the Sahara Desert during spring migration use some day flight in order to complete the crossing of this inhospitable barrier [2-4]. For other migratory land birds, day-night divides may be more impermeable barriers to migratory activity, or alternatively, flight pattern structure may be maintained despite changes in light regimes. For example, some nocturnal species, such as nightjars, may be restricted to nocturnal migration throughout their journeys $[6,7]$ and some diurnal migrants moving north of the arctic circle may maintain the timing and duration of their diurnal flights, even when there are longer hours of daylight available [8].

Diurnally migrating birds need to both migrate and forage during the daytime and may adopt a fly-andforage strategy, where they both migrate and refuel during the day $[9,10]$. A fly-and-forage strategy may be supported by foraging opportunities that may occur during flight (such as for aerial insectivores), or at pauses during, or after, daily migratory flights $[4,10]$. It is predicted that diurnal migrants may incorporate nocturnal flights when they cannot benefit from energy deposition during a fly-and-forage strategy, such as when crossing ecological barriers or habitats with sub-optimal foraging [4]. Diurnal Eleonora's falcons (Falco eleonorae) were found to be flexible in their use of day or night flights during migration, particularly when crossing ecological barriers that did not provide insect rich areas for foraging [11]. However, whether diurnally migrating songbirds presumed to use a fly-and-forage strategy of migration, such as swallows, use nocturnal flight during migration has been little investigated [12]. Recent investigations of swallow diurnal versus nocturnal movements confirmed only daytime movements [12]. Recent migration tracking of some diurnally migrating species at large barrier crossings suggest some night flight may be incorporated, because duration of crossing seemed to exceed daylight hours $[13,14]$. However, this has not been directly examined.

The diversity of migration timing strategies, especially in ecological barrier crossing, can also reflect species-specific, or intraspecific strategies $[4,5]$. For example, whinchats (Saxicola rubetra) crossing the Sahara Desert had higher predicted migration speeds as compared to when crossing the Mediterranean Sea, which is a considerably narrower barrier [15]. Investigations of the flexibility of diurnal or nocturnal migration over ecological barriers (water or land) and across full migratory routes remain rare. New, high spatio-temporal precision in tracking technology that can be applied to studies of even small $(<100 \mathrm{~g}) \mathrm{mi}$ grants offers new opportunities to investigate migration timing strategies on a circadian scale.
As a trans-hemispheric long-distance migratory swallow, purple martins (Progne subis) are thought to be exclusively diurnal birds that feed and migrate during the day using a fly-and-forage strategy [16]. They migrate up to $10,000 \mathrm{~km}$ seasonally between North American breeding sites and South American overwintering sites choosing migratory routes that cross over the Gulf of Mexico or the Caribbean Sea, suggesting some night flight may be used to complete the crossings [13, 14]. Our aim in this study was to apply high precision tracking to determine whether this diurnal songbird uses both day and night flight to accomplish large ocean barrier crossings during spring migration, and/or whether they use nocturnal flights generally during their migrations. Through this investigation, we tested the hypotheses that, 1) these diurnal migrants may incorporate night flight at barrier crossing where foraging opportunities are suboptimal, and 2) that night flights are associated with advantages of facilitating winds and/or a reduction of migration distance as a component of time- or energy-saving strategies [4].

\section{Methods}

During the 2017 to 2019 breeding season, we deployed a total of 98 GPS units (Pinpoint 10, Lotek Inc.) on adult purple martins at four North American breeding locations (supplemental material, Table A). Purple martins were captured using drop-door traps at their nest boxes. GPS units were mounted onto adults using a leg-loop backpack harness made of Teflon ribbon [17]. The mass of tag $(1.5 \mathrm{~g})$ and harness was less than $3 \%$ of an adult purple martin's body mass.

Tags were pre-programmed to collect positional fixes across spring migration (January to April) at prescribed times that enabled the partitioning of day versus night flights. We programmed tags to align with breeding population-specific timing (FL: January, TX: March, MB: April; Table 1), previously identified through the use of light-level geolocators ([13, 14], Fraser et al. unpub. data), to capture the spring migration routes and timing we required for this investigation. Tags were programmed to detect and save locations two or three times a day: 0600 and $1800 \mathrm{~h}$ Central Daylight Time (CDT) ( $n=8$, Manitoba (MB) and Texas (TX) colonies); 0400 and $1600 \mathrm{~h}$ Eastern Daylight Time (EDT) $(n=2$, Pennsylvania (PA) and Florida (FL)); 0400, 1000, and $1600 \mathrm{~h}$ $(\mathrm{CDT})(n=1, \mathrm{TX}) ; 0000,0600$ and $1800 \mathrm{~h}(\mathrm{CDT})(n=1$, TX). Detections at $0000-\mathrm{h}$ and at $1800 \mathrm{~h}$ both reflected a portion of nocturnal flight [7], and therefore were combined to create a 12-h night flight interval to make data comparable to those from other tags. Similarly, detections at $1000 \mathrm{~h}$ were combined with detections at $0400 \mathrm{~h}$ to make a 12-h day flight interval for better comparison with other tags. 
Table 1 Location, timing, and other migration track details of each individual purple martin used in this study. A total of their day and night flights over water was calculated using GPS positions logged every $12 \mathrm{~h}$

\begin{tabular}{llllllll}
\hline Bird ID & Sex & $\begin{array}{l}\text { Breeding } \\
\text { ground }\end{array}$ & $\begin{array}{l}\text { Wintering } \\
\text { location (lat., long.) }\end{array}$ & $\begin{array}{l}\text { Migration } \\
\text { track start }\end{array}$ & $\begin{array}{l}\text { Migration } \\
\text { track end }\end{array}$ & $\begin{array}{l}\text { Number of day } \\
\text { flights over water }\end{array}$ & $\begin{array}{l}\text { Number of night } \\
\text { flights over water }\end{array}$ \\
\hline 1598 & M & Florida & $-2.31,-54.12$ & $26 / 01 / 2018$ & NA & 1 & 2 \\
1602 & M & Florida & $-1.15,-62.09$ & $14 / 01 / 2018$ & $5 / 02 / 2018$ & 3 & 2 \\
2810 & F & Texas & $-1.37,-61.70$ & $08 / 03 / 2020$ & NA & 1 & 2 \\
48041 & M & Texas & $7.84,-69.95$ & $12 / 03 / 2018$ & $15 / 04 / 2018$ & 2 & 2 \\
48042 & F & Texas & NA & $12 / 03 / 2018$ & $22 / 03 / 2018$ & 1 & 1 \\
48045 & F & Texas & $-3.78,-58.3$ & $27 / 03 / 2018$ & $17 / 04 / 2018$ & 2 & 2 \\
48046 & M & Texas & $-2.83,-60.51$ & $30 / 03 / 2018$ & $20 / 04 / 2018$ & 3 & 3 \\
48051 & F & Texas & $-6.84,-51.7$ & $14 / 03 / 2018$ & $16 / 04 / 2018$ & 1 & - \\
48052 & M & Texas & $-2.12,-55.56$ & $17 / 03 / 2018$ & $4 / 04 / 2018$ & 3 & 2 \\
48794 & M & Texas & $16.06,-89.12$ & $12 / 03 / 2019$ & $29 / 03 / 2019$ & 1 & 2 \\
2177 & M & Manitoba & $2.36,-65.23$ & $18 / 04 / 2019$ & $07 / 05 / 2019$ & 3 & \\
\hline
\end{tabular}

GPS units were retrieved in the year following deployment using the same methods of capture. PinPoint Host software (Lotek Inc.) was used for data extraction. We defined flights between 1800 to 0600 and 1600 to $0400 \mathrm{~h}$ as nocturnal flight and those between 0600 to 1800 and 0400 to 1600 as diurnal flight. Migration distances were measured using Google Earth [18] and as geodesic distances $(\mathrm{km})$ between fixes using the R package geosphere [19].

Because the GPS tags collected locations on fixed schedules, the amount of daylight that occurred during the tracking periods varied as the season progressed and birds moved substantial distances. We determined the amount of available daylight in each $12 \mathrm{~h}$ track segment to address the possibility that some daylight was present during the 'nighttime' flight segments. Daylight hours are defined as the time between sunrise and sunset ( $\mathrm{R}$ package suncalc [20]), and the amount of daylight per track was calculated according to the GPS locations and fix times at the beginning and end of a $12 \mathrm{~h}$ track segment (i.e. time between sunrise or sunset at the bird's start location and sunset or sunrise at the bird's end location). Log-transformed distances were regressed against amount of daylight in the $12 \mathrm{~h}$ segments in a linear model ( $n=190$ day segments, 203 night segments).

\section{Barrier-crossing model}

We tested the effect of wind assistance and potential distance savings on the decision to cross a waterbody or detour around it. We used the last GPS location recorded for each individual before their track either continued across a waterbody $(n=22)$, or reoriented to circumnavigate the waterbody $(n=6)$, and classified those departure points into binary categories of 'cross' or 'detour'.

\section{Distance savings (water:land) covariate}

We compared the distances of water crossings to circumnavigations around those waterbodies, which represent the alternatives that a bird would have when faced with a decision at the coast to launch a water crossing or reorient to remain over land. For each track that crossed a waterbody, we measured the corresponding hypothetical circumnavigational route distance, using the minimum number of connecting lines required to constrain the path over land. Conversely, where a bird had actually circumnavigated a waterbody, we measured the hypothetical water crossing distance to represent the alternative route. Here, we measured the geodesic distance between the GPS location at the departure point (the point at which the bird had made the decision to reorient) and the next closest GPS location on the far side of the waterbody. This GPS location was always a point after which the bird was moving away from the waterbody, in a northbound migration direction. For each individual at each waterbody, we divided the water crossing distance by the circumnavigation distance to obtain a ratio. A ratio close to one indicates that the distances to follow a land or water route are similar, and the distance saved by crossing the waterbody is minimal.

\section{Tailwind assistance covariate}

We used the R package RNCEP [21] to retrieve surfacelevel $U$ (east-west) and V (north-south) wind components from the NCEP/NCAR Reanalysis data provided by the NOAA/OAR/ESRL PSL, Boulder, CO, USA [22, 23]. Wind components for each departure point were interpolated from a global grid with a spatial resolution of $2.5^{\circ}$ latitude and $2.5^{\circ}$ longitude and a temporal resolution 
of $6 \mathrm{~h}$ (daily at $00,06,12$, and $18 \mathrm{~h}$ UTC), using the function 'NCEP.interp()' with the default parameter of linear interpolation. We assigned an optimal direction for each waterbody crossing, based on the observed migratory routes and known breeding destinations of individual birds. The optimal direction for all birds to cross the Caribbean Sea was west $\left(270^{\circ}\right)$, the Gulf of Honduras was northwest $\left(315^{\circ}\right)$, and the optimal direction to cross the Gulf of Mexico varied from northwest $\left(315^{\circ}\right)$, to north $\left(0^{\circ}\right)$, or northeast $\left(45^{\circ}\right)$, for individuals migrating to Texas, Manitoba, or Florida, respectively. We derived the tailwind assistance $(\mathrm{m} / \mathrm{s})$ at each departure point from the $\mathrm{U}$ and $\mathrm{V}$ wind components, using the RNCEP function 'NCEP.Tailwind()' [21]. We specified optimal direction for each crossing as the assumed preferred flight direction, and did not specify airspeed. The value of the tailwind assistance will be positive when the wind is flowing in the optimal direction of travel, and negative for wind flowing against the optimal direction (i.e. headwind). We scaled and centered the variables of distance savings and tailwind assistance for easier comparison in a linear mixed model using the $\mathrm{R}$ function 'scale()'. We tested the likelihood of crossing over a waterbody in a logistic regression, with tailwind assistance and water: land distance ratio as fixed effects, and individual bird as a random effect to control for repeated measures of individuals that made multiple water crossings.

To visualize the distribution of winds available at departure locations and times compared to the birds' decisions to cross or detour around waterbodies, we calculated windspeed $(\mathrm{m} / \mathrm{s})$ and direction (with $0^{\circ}$ as north) from the $\mathrm{U}$ and $\mathrm{V}$ wind vectors using the $\mathrm{R}$ package $r$ Wind [24]. We plotted windroses [25] of windspeed and direction frequency, and circular histograms of birds' track bearings. Our sample size for the windrose and histogram for water crossings $(n=23)$ included one additional departure point that was excluded from the model because we did not have a GPS location over land, and therefore could not confidently calculate a distance ratio.

\section{Statistical analyses}

We used $\mathrm{R}$ version 4.0.3 for all statistical analyses [26]. We used the Bayesian package brms [27] to fit the linear mixed models, which were run with default uninformative priors, four chains, and a minimum of 2000 iterations. We examined model residuals to confirm that variables reasonably met linearity assumptions, and models were validated with posterior predictive checks to ensure complete mixing of chains and that posterior distributions did a good job of predicting new data. We calculated $\mathrm{R}^{2}$ for Bayesian models to evaluate the proportion of variance explained by the model terms [28]. All model results reported include 95\% Bayesian credible intervals (CI). Maps were created in ArcGIS 10.7 [29].

\section{Results}

During the breeding seasons of 2018-2020 we retrieved 12 GPS units $(n=2 \mathrm{FL}, n=9 \mathrm{TX}, n=1 \mathrm{MB})$. A tag retrieved in Texas recorded only 12 fixes and was excluded from our analysis. Among the remaining 11 tags, two began recording migration en route and two tags stopped recording data before birds reached their breeding sites (Figs. 1, 2). The number of useable points per individual ranged between 45 and 80 fixes per GPS unit (recorded over a sampling period up to $\sim 40$ days) with a total of 710 points from all 11 retrieved tags. After removing the points recorded outside of the migratory period (at breeding and wintering sites), a total of 461 points were used for further analysis of spring migration. Spring migration routes and timing fell within the range of what had been previously recorded when using lightlevel geolocator tags for these same breeding populations ([13, 14], Fraser et al. unpublished data). Tag retrieval rates $(\sim 12 \%)$ were lower than previously reported in this species when using the same GPS units (tag retrieval at $17 \%$, [30]), or when using tracking tags of similar weight and dimensions (retrieval rate of geolocators at 21-61\%, $[30,31])$, and as compared to return rates for birds that were banded only (25-48\%, [31]).

We found that 10 of 11 birds made large, open-water crossings during spring migration that included night flight (Table 1). These open water flights occurred when birds crossed the Caribbean Sea (which includes the Gulf of Honduras) or the Gulf of Mexico. Total, straight line distances between GPS locations for these openwater crossings ranged from 96.9-1107 km. The average total distance for night flights over water per individual was $357.11 \pm 25.69 \mathrm{~km}$ compared to $559.79 \pm 49.82 \mathrm{~km}$ for flights over water during the day (Fig. 2). The average total spring migration distance for Texas birds was $6526.85 \pm 660.98 \mathrm{~km}$ and for Florida birds was approximately $5530.53 \pm 474.66 \mathrm{~km}$. The total migration distance for the Manitoba bird was $7611.8 \mathrm{~km}$ (Table 2). All birds that made some crossing of the Caribbean Sea $(n=8)$ and the Gulf of Mexico $(n=8)$ used night flight. Six birds (55\%) that made large crossings of the Caribbean Sea or the Gulf of Mexico initiated these crossings during dark hours, not only at the end to complete the crossings. All 11 birds also made small, overland flights at night that were not associated with barrier crossing.

Among the birds that migrated to Florida, Texas, and Manitoba, the longest straight-line distance between points covered within $24 \mathrm{~h}$ occurred while birds were migrating over the Caribbean Sea. These included a $1222 \mathrm{~km}$ total flight with $1006 \mathrm{~km}$ occurring over water (bird ID 1602, FL colony), a $1378 \mathrm{~km}$ total flight with $852.56 \mathrm{~km}$ 


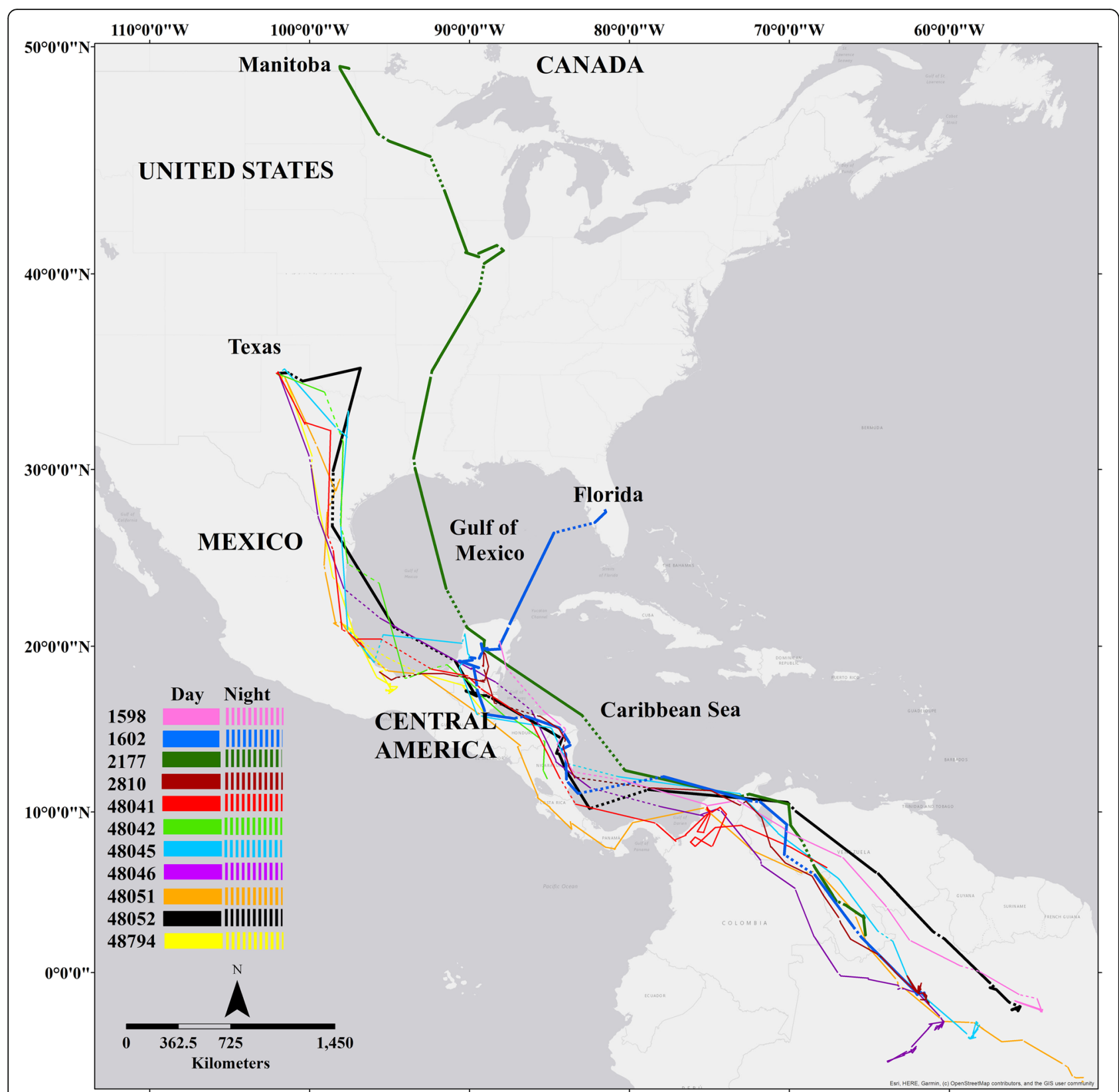

Fig. 1 Global Positioning System locations of eleven spring migration tracks of purple martins from 2018 to 2020 during spring migration to three breeding locations (Texas and Florida, USA and Manitoba, Canada) from their South American overwintering grounds. Straight lines connect GPS locations and do not necessarily reflect true migratory paths

occurring over water (bird ID 48052, TX colony), and a $1274 \mathrm{~km}$ total flight with $1107 \mathrm{~km}$ occurring over water (bird ID 2177, MB colony; Fig. 2). The mean flight distance in $24 \mathrm{~h}$ was approximately $295.03 \pm 17.9 \mathrm{~km}$.

Migration speed over open water was highest over the Caribbean Sea at $79 \mathrm{~km} / \mathrm{h}$ during the day (tag ID 48052 ) and $50 \mathrm{~km} / \mathrm{h}$ at night (tag ID 1602). The highest migration speed during the day over land was 57 $\mathrm{km} / \mathrm{h}$ (tag ID 48794) and $32 \mathrm{~km} / \mathrm{h}$ at night (tag ID
1598; Table 3). The total average migration speed was $12 \pm 0.70 \mathrm{~km} / \mathrm{h}$.

During predominantly daytime flights, an increase in available daylight did not influence distances (log $\mathrm{km}$ ) traveled (slope 0.0024 [-0.0017, 0.0067]; Supplemental Fig. S1a), but there was a statistically significant positive effect during predominantly nighttime flights (slope 0.013 [0.0065, 0.019]; Supplemental Fig. S1b). The amount of daylight that occurred within the nighttime 


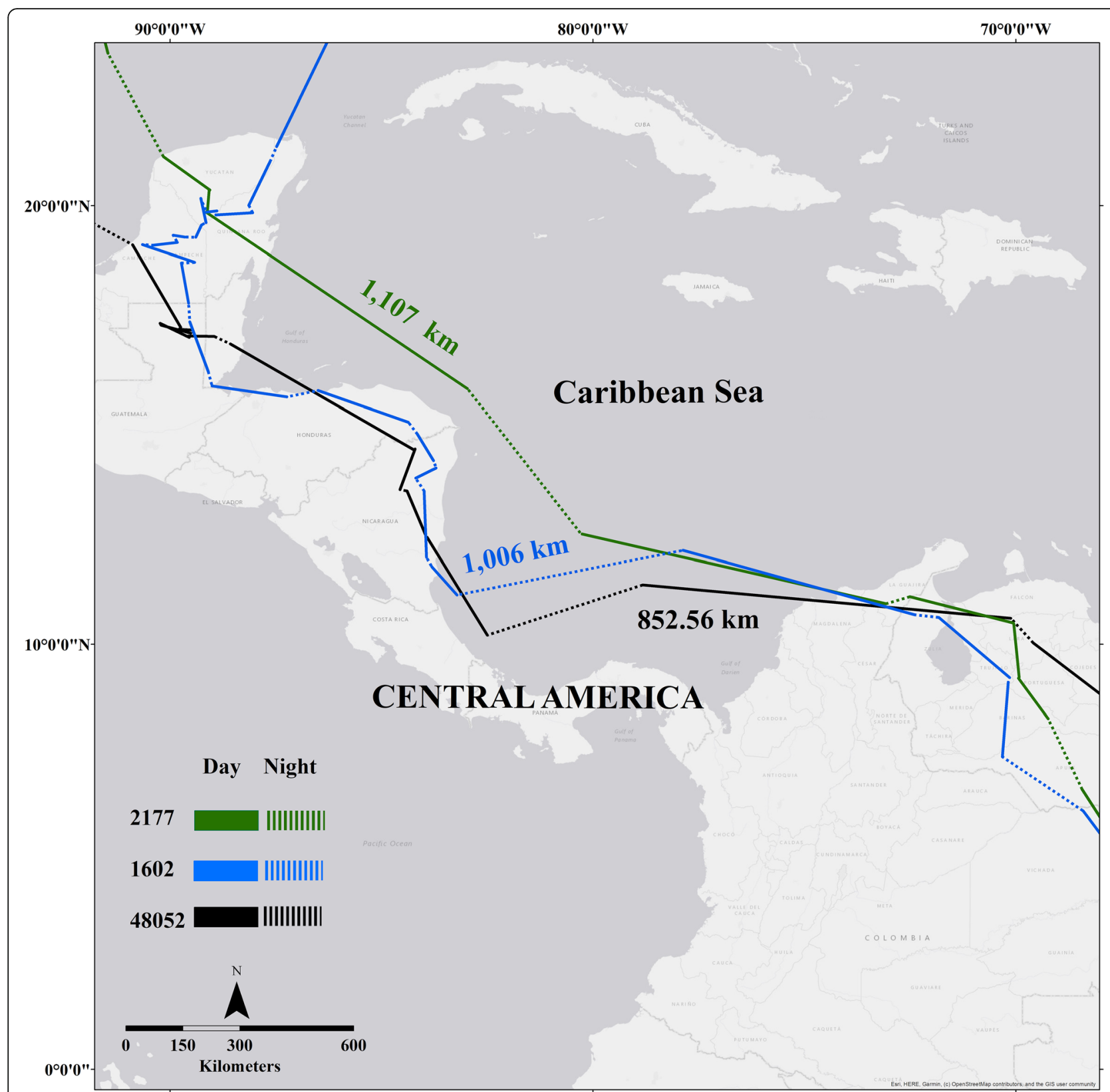

Fig. 2 Longest migration distances over a 24-h span crossing the Caribbean Sea for three purple martins returning to their breeding grounds in Manitoba, Canada (2177), Florida (1602) and Texas, USA (48052). Distances represent straight line flight over water and do not necessarily reflect exact flight paths

flight segments ranged from four to 176 min (mean 67 min, SD 40), and the distance flown during the nighttime flights ranged from zero to $594 \mathrm{~km}$ (mean $68 \mathrm{~km}$, SD 110). Within the nighttime flight segments, a $50 \%$ increase in amount of daylight would correspond to a predicted mean $0.5 \%$ increase in distance traveled.

The probability of purple martins initiating a water crossing, rather than detouring to circumnavigate over land, decreased as the water to land ratio increased, and the potential distance savings thus decreased (Table 4, Figs. 3,4$)$. That is, when the distances of a water crossing and the alternative circumnavigation were similar, birds were more likely to take the overland route than the overwater route. Seven of the 22 water crossings, and five of the six detours, were initiated during night, and we did not detect an effect of time of day (day versus night) on the decision to initiate water crossings. The Bayes $\mathrm{R}^{2}$ for this model was 0.30 (Estimated Error: 
Table 2 Total migration distance for 11 purple martins with the mean and standard errors calculated for the distance travelled over land and water during the day and night

\begin{tabular}{lllllll}
\hline Bird ID & $\begin{array}{l}\text { Breeding } \\
\text { ground }\end{array}$ & $\begin{array}{l}\text { Total distance } \\
(\mathbf{k m})\end{array}$ & $\begin{array}{l}\text { Distance over land/day } \\
(\mathbf{k m})(\mathbf{m e a n} \pm \mathbf{S E})\end{array}$ & $\begin{array}{l}\text { Distance over land/night } \\
(\mathbf{k m})(\mathbf{m e a n} \pm \mathbf{S E})\end{array}$ & $\begin{array}{l}\text { Distance over water/day } \\
\mathbf{( k m})(\mathbf{m e a n} \pm \mathbf{S E})\end{array}$ & $\begin{array}{l}\text { Distance over water/ } \\
\mathbf{n i g h t}(\mathbf{k m}) \mathbf{( m e a n} \pm \mathbf{S E})\end{array}$ \\
\hline 1598 & Florida & 4859.26 & $258.77 \pm 34.75$ & $43.71 \pm 14.38$ & $592 \pm 0.00$ & $362.50 \pm 16.62$ \\
1602 & Florida & 6201.80 & $151.81 \pm 28.96$ & $44.90 \pm 10.98$ & $452.63 \pm 145.31$ & $432.5 \pm 119.85$ \\
2810 & Texas & 3907.73 & $240.28 \pm 25.16$ & $45.39 \pm 13.08$ & $630 \pm 0.00$ & $419 \pm 74.95$ \\
48041 & Texas & 7138.05 & $163.29 \pm 26.59$ & $13.30 \pm 3.75$ & $353.5 \pm 141.77$ & $302 \pm 61.51$ \\
48042 & Texas & 3620.68 & $206.49 \pm 37.89$ & $68.50 \pm 28.43$ & $635.69 \pm 0.00$ & $235 \pm 0.00$ \\
48045 & Texas & 8079.28 & $275.04 \pm 45.72$ & $34.12 \pm 7.03$ & $672.5 \pm 109.95$ & $275.5 \pm 59.74$ \\
48046 & Texas & 6784.23 & $209.21 \pm 36.37$ & $22.05 \pm 4.37$ & $428 \pm 104.19$ & $368.66 \pm 52.39$ \\
48051 & Texas & 8397.53 & $200.92 \pm 21.80$ & $37.35 \pm 7.69$ & $497 \pm 0.00$ & 0.00 \\
48052 & Texas & 7515.37 & $235.98 \pm 57.95$ & $50.63 \pm 19.13$ & $666.33 \pm 159.49$ & $440 \pm 173.05$ \\
48794 & Texas & 4152.84 & $187.07 \pm 43.88$ & $24.17 \pm 5.27$ & $154.00 \pm 0.00$ & $417.00 \pm 0.00$ \\
2177 & Manitoba & 7611.80 & $207.98 \pm 33.37$ & $53.23 \pm 14.42$ & $787.67 \pm 8.03$ & $377.50 \pm 65.40$ \\
\hline
\end{tabular}

$0.10 ; \mathrm{CI}=0.10-0.50)$. Winds at the departure points and times were predominantly to the southwest for both water crossings and detours, whereas the birds' flight directions were predominantly to the northwest during crossings and west-southwest for detours (Fig. 5).

\section{Discussion}

Our study provides the first tracking evidence that swallows, generally considered to be diurnal migrants, can also incorporate night flights into their migrations, particularly when crossing large, open-water barriers. The use of night flights in species usually characterized as diurnal, fly-andforage, migrants was predicted to occur at areas with reduced foraging opportunities, such as at barrier crossing [4]. This has recently been shown in falcons [11], but had not been demonstrated for diurnal songbirds such as swallows, that commonly cross ecological barriers [13, 14] where some night flight was also predicted to be required to cross such great distances. Our migration-tracking of purple martins using high precision GPS units support hypotheses for the use of nocturnal flights at barrier crossing by otherwise diurnal migrants [4] and builds upon other recent migration-tracking evidence demonstrating the combination of day and night flights in long-distance migration (e.g. [32]). Our results are consistent with the notion that these primarily diurnal birds use night flight, particularly when making large open-water crossings, to help achieve time- and energy-savings when foraging conditions are suboptimal.

Ten of the eleven purple martins that we tracked used night flight when crossing over water. In some ways this would be expected as birds crossing open water at distances greater than $1000 \mathrm{~km}$ would not have anywhere to stop for rest, and with flight speeds of $19-36 \mathrm{~km} / \mathrm{h}$, could

Table 3 Average migration speed over land and water $(\mathrm{km} / \mathrm{h})$ during the day and night as well as highest migration speed over land and water during the day and night (km/h). C: over Caribbean Sea, G: over Gulf of Mexico

\begin{tabular}{|c|c|c|c|c|c|c|c|c|c|}
\hline ID & $\begin{array}{l}\text { Breeding } \\
\text { ground }\end{array}$ & $\begin{array}{l}\text { Migration } \\
\text { speed land/ } \\
\text { day (mean } \pm \\
\text { SE) }\end{array}$ & $\begin{array}{l}\text { Migration } \\
\text { speed land/ } \\
\text { night } \\
\text { (mean } \pm \mathrm{SE} \text { ) }\end{array}$ & $\begin{array}{l}\text { Migration } \\
\text { speed water/ } \\
\text { day (mean } \pm \\
\text { SE) }\end{array}$ & $\begin{array}{l}\text { Migration } \\
\text { speed water/ } \\
\text { night (mean } \pm \\
\text { SE) }\end{array}$ & $\begin{array}{l}\text { Highest } \\
\text { migration } \\
\text { speed land/ } \\
\text { day }\end{array}$ & $\begin{array}{l}\text { Highest } \\
\text { migration } \\
\text { speed land/ } \\
\text { night }\end{array}$ & $\begin{array}{l}\text { Highest } \\
\text { migration } \\
\text { speed } \\
\text { water/day }\end{array}$ & $\begin{array}{l}\text { Highest } \\
\text { migration } \\
\text { speed water/ } \\
\text { night }\end{array}$ \\
\hline 1598 & Florida & $22 \pm 5$ & $4 \pm 4$ & $50 \pm 0$ & $30 \pm 1$ & 37 & 32 & $49 C$ & $28 C$ \\
\hline 1602 & Florida & $13 \pm 2$ & $4 \pm 1$ & $38 \pm 12$ & $36 . \pm 1$ & 45 & 21 & $53 \mathrm{G}$ & $50 \mathrm{C}$ \\
\hline 2810 & Texas & $21 \pm 2$ & $4 \pm 1$ & $53 \pm 0$ & $35 \pm 6$ & 31 & 14 & $53 C$ & $43 C$ \\
\hline 48041 & Texas & $14 \pm 2$ & $1 \pm 0$ & $30 \pm 12$ & $2 \pm 5$ & 53 & 9 & $46 C$ & $32 \mathrm{G}$ \\
\hline 48042 & Texas & $17 \pm 3$ & $6 \pm 2$ & $53 \pm 0$ & $20 \pm 0$ & 42 & 26 & $53 \mathrm{G}$ & $19 \mathrm{G}$ \\
\hline 48045 & Texas & $23 \pm 4$ & $3 \pm 1$ & $56 \pm 9$ & $23 \pm 5$ & 57 & 11 & $69 C$ & $30 \mathrm{C}$ \\
\hline 48046 & Texas & $17 \pm 3$ & $2 \pm 0$ & $36 \pm 9$ & $31 \pm 4$ & 42 & 7 & $57 \mathrm{G}$ & $41 \mathrm{C}$ \\
\hline 48051 & Texas & $17 \pm 25$ & $3 \pm 1$ & $41 \pm 0$ & 0 & 34 & 18 & $41 \mathrm{C}$ & 0 \\
\hline 48052 & Texas & $20 \pm 5$ & $4 \pm 1$ & $56 \pm 13$ & $37 \pm 1$ & 57 & 28 & $80 \mathrm{C}$ & $38 \mathrm{G}$ \\
\hline 48794 & Texas & $16 \pm 4$ & $2 \pm 4$ & $13 \pm 0$ & $35 \pm 0$ & 57 & 6 & $29 \mathrm{G}$ & $19 \mathrm{G}$ \\
\hline 2177 & Manitoba & $17 \pm 3$ & $4 \pm 1$ & $66 \pm 1$ & $31 \pm 5$ & 43 & 17 & $67 C$ & $39 \mathrm{C}$ \\
\hline
\end{tabular}


Table 4 Logistic regression results for covariates predicting whether migrating purple martins will cross, or detour around, waterbodies. Tailwind is the wind assistance $(\mathrm{m} / \mathrm{s})$ in the optimal direction of travel; Water:Land refers to distance saved by crossing a waterbody (higher ratio = less distance saved), and DayOrNight is time of day that flights were initiated. $\mathrm{Cl}=$ lower and upper Bayesian credible intervals. Continuous variables were scaled and centered prior to analysis

\begin{tabular}{llllllll}
\hline Covariate & Estimate & Est.Error & I-95\% Cl & u-95\% Cl & Rhat & Bulk_ESS & Tail_ESS \\
\hline Intercept & 3.24 & 1.57 & 0.88 & 7.16 & 1.00 & 2538 & 1744 \\
Tailwind & 1.25 & 0.86 & -0.28 & 3.15 & 1.00 & 5795 & 4345 \\
Water:Land & -2.04 & 1.18 & -4.86 & -0.23 & 1.00 & 3319 & 1971 \\
DayOrNight & -1.47 & 1.62 & -5.20 & 1.22 & 1.00 & 3213 & 1871 \\
\hline
\end{tabular}

not complete the crossing during $12 \mathrm{~h}$ of daylight [33]. Large barrier crossings may generally require that chiefly nocturnal or diurnal migrants include flights during light conditions when they do not typically migrate. Despite a high prevalence of nocturnal flight in our study, the average migration distance over water was greater during the day as compared to the night. In part, this may be due to night flight being used primarily to finish off the crossing of ecological barriers (12 of 19 of the total number of open-water flights at night were to complete crossings). Similar to our findings for flights extending to cross daynight boundaries, several species of songbird incorporate some daytime flight into their otherwise nocturnal migrations in order to finish the crossing of the expansive migration barrier of the Sahara Desert [3, 5, 34].

However, we also found that $32 \%$ of all open water crossings were initiated at night. Night flights were therefore not only used to complete crossings initiated during daytime as could be predicted based upon distances and expected rates of travel for diurnal migrants crossing ecological barriers $[9,16]$. Our results support optimal timing

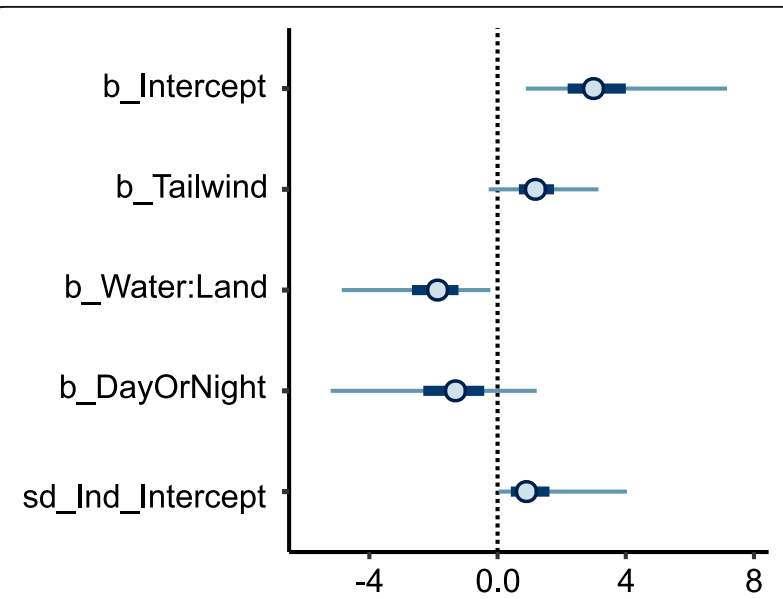

Fig. 3 Bayesian linear mixed model coefficients for the effects of tailwind assistance, water:land distance ratio, and time of day on purple martin water crossings. Only the distance ratio had a significant effect on decisions to initiate water crossings (they were less likely to cross a water body as the distance savings decreased). Coefficient estimates are shown with 50 and $95 \%$ credible intervals. Continuous variables were scaled and centered prior to analysis hypotheses for fly-and-forage migrants, where it is predicted that daily travel schedules may shift toward night flights in areas that do not offer good foraging opportunities [4]. Ocean crossing during dark hours may confer time- or energy-savings while supporting an otherwise diurnal, fly-and-forage, migratory strategy in songbirds. Aerial insectivores such as purple martins and other swallows may be able to catch insect prey while heading in a general migratory direction during the day or make short stops or detours to accomplish this task while maintaining their migration [9]. Or, migratory flights may be undertaken in the morning daylight hours, leaving the afternoon for foraging and refueling [4]. Indeed, such a strategy may be evident in bank swallows (Riparia riparia), where during fall migration travel speeds were slower, suggesting they were actively refueling while migrating [35]. However, the degree to which other swallow species use a fly-and-forage strategy, and the conditions that promote its use, require further investigation using migration tracking.

During open-ocean or other barrier crossing, the advantages of being able to forage while migrating may be reduced or eliminated, as aerial insect availability may be limited or absent over open ocean [4]. Birds that engage in ocean crossing and incorporate night flights may reflect a time- and/or energy-minimization strategy [36, 37], where barrier crossing at the Caribbean Sea or Gulf of Mexico may greatly reduce overall distances travelled, and thus minimize the overall time and energy required to complete spring migration [35, 36]. Indeed, the ocean crossings we documented reflect significant 'short cuts', as compared to an overland route throughout the same regions (e.g. Gulf of Mexico crossing $871 \mathrm{~km}$ versus around at $937 \mathrm{~km}$ ).

In addition to large, open-water flights at night, we observed shorter night flights over land. Average night flights over land were also much shorter than average daytime flights over land. Like night flights over water where foraging opportunities are low, night flights over land may also occur over areas that offer limited foraging opportunities [4]. However, some of the flights we documented as short 'night' flights, occurred around sunrise or sunset and therefore could have been completed in the twilight hours. A positive relationship between 'nighttime' flight distances and amount of daylight 

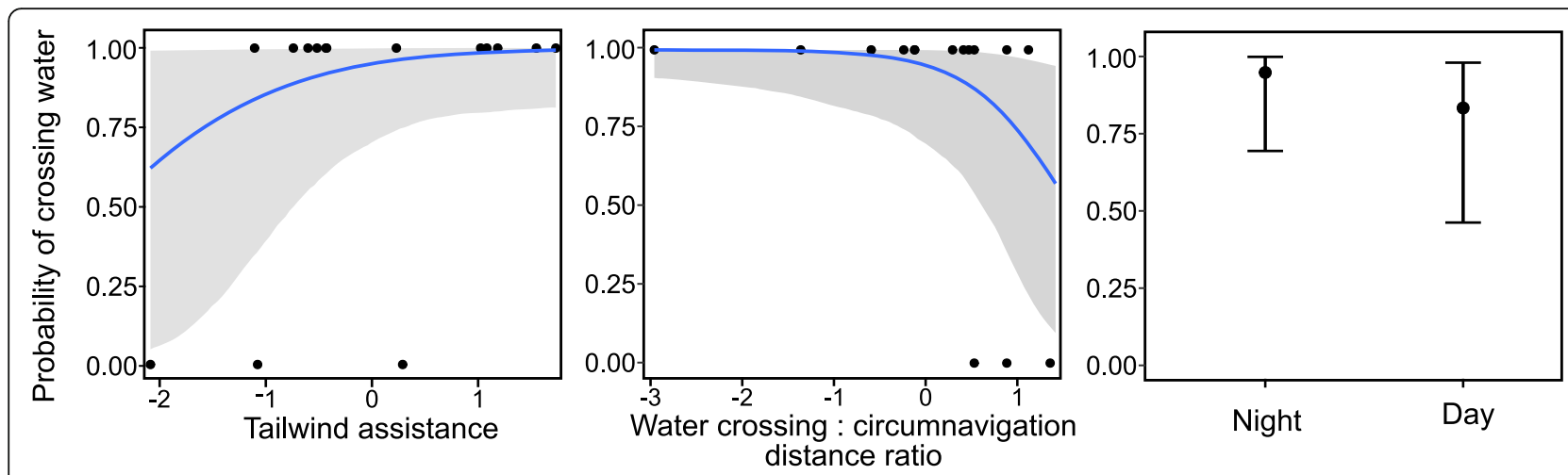

Fig. 4 The predicted probability of purple martins initiating a water crossing, rather than detouring to circumnavigate over land, does not increase significantly with an increase in tailwind assistance in the optimal direction of travel (left), or during night vs day (right). Probability of crossing decreases significantly as the water to land ratio increases, and the potential savings in distance therefore decrease (center). Shading represents 95\% Bayesian credible intervals. Continuous variables were scaled and centered prior to analysis

available during each $12 \mathrm{~h}$ track segment (Supplemental Figure S1b) indicates that some 'night' flights likely took place during daylight hours near sunrise or sunset. Indeed, four swallow species that utilize a fly-and-forage strategy migrated during twilight as revealed through automated radio telemetry [12].
Our data indicate that the probability that purple martins will initiate water crossings during northbound spring migration does not increase significantly with stronger winds flowing in a direction that would support travel in optimal directions (Table 4, Figs. 3, 4). However, wind measured on the days that martins navigated

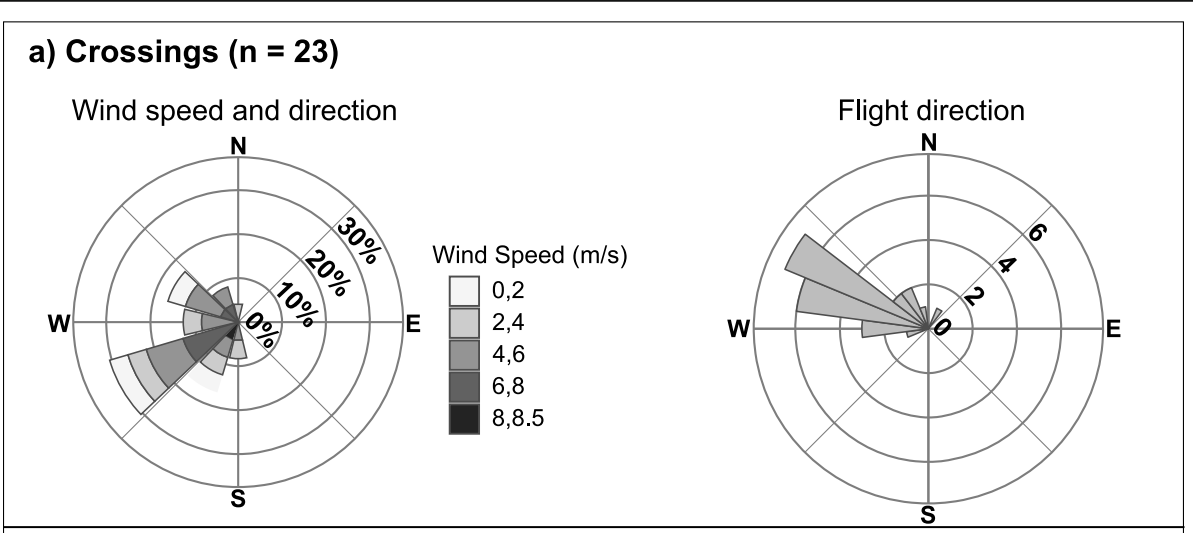

b) Detours ( $n=6)$

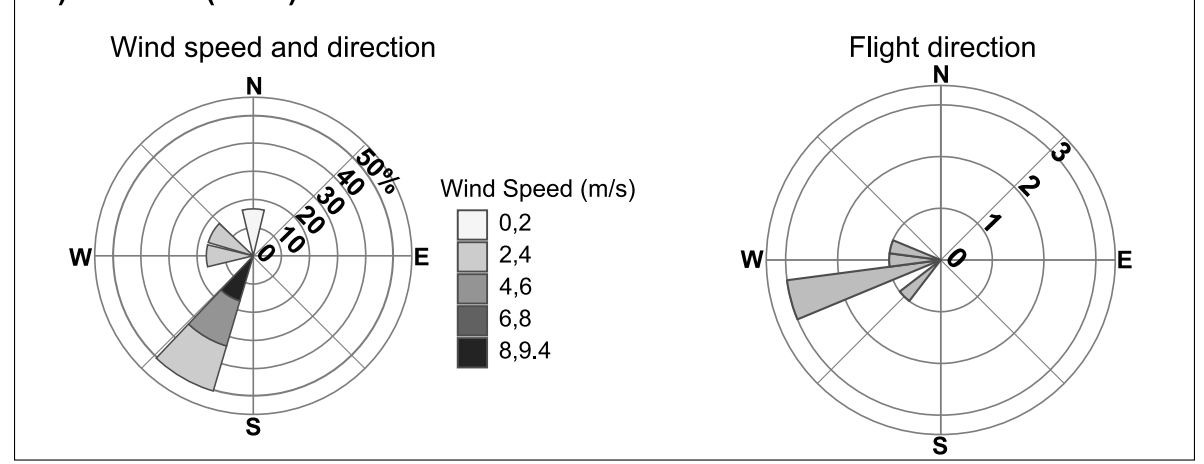

Fig. 5 Windroses of the frequency of wind speeds at departure points for purple martins that either crossed (a) or detoured (b) around waterbodies (left in each panel). Corresponding histograms of flight directions from GPS tracked individuals (right in each panel). Bars on all plots indicate the directions that wind or flights are moving toward: winds during both crossings and detours flowed predominantly toward the southwest, and bird flights were directed predominantly toward the northwest (crossings) and west-southwest (detours) 
waterbodies, whether by crossing or detouring, were predominantly to the southwest, which would not confer an advantage to birds traveling predominantly to the northwest (Fig. 5). These results align with some previous observations for night-migrating passerines, where there was little selection for facilitating winds and individuals continued directional migration flights despite variation in wind direction and strength [38].

Variation in survival rates between years and sites could have contributed to the variation in tag retrieval within our study and the lower tag retrieval rate overall. Generally, tagged birds in this species tend to have similar return rates to birds that were banded only [30] and different tag types deployed in the same year at the same sites had comparable return rates [29]. However, since this study was not designed to test for factors contributing to tag retrieval rate, we cannot rule out a potential tag effect on survival. Further, sampling and re-sighting methods were not necessarily consistent across sites within this study or as compared to earlier studies, e.g., re-sighting, re-capture, and initial tagging occurred at varying times within the nesting cycle at different sites which could have contributed to variation in tag retrieval rates. A future study aimed specifically at investigating factors that may contribute to the retrieval rates of GPS units could better identify factors that influence retrieval rates.

\section{Conclusion}

This is the first study of a swallow to examine circadian patterns of flight across migration to see how selection has potentially shaped day-night circadian migratory behaviours. Our study demonstrates that a species generally considered to be a diurnal migrant incorporates a large amount of nocturnal flight into its migrations, particularly at barrier crossing. Night flights in an otherwise diurnal species, may be favoured where foraging opportunities are low and to contribute to a time- and energysaving strategy. Future research could further target within-day patterns of movement, to test hypotheses for how diel foraging and refueling patterns may support the combination of night and day flights and the advantages of nocturnal open-water crossing in otherwise diurnal migrants.

\section{Supplementary Information}

The online version contains supplementary material available at https://doi. org/10.1186/s40462-021-00257-7.

Additional file 1: Table A. Four breeding colonies of purple martins (Progne subis) along with the number of GPS units (Lotek) deployed and retrieved at each site for spring migration tracking (2017-2020). Figure S1. Relationship between distance traveled by Purple Martins and amount of daylight available in each $12 \mathrm{~h}$ tracking period. Daylight hours are defined as the time between sunrise and sunset, and the amount of daylight per track was calculated according to the GPS locations and fix times at the beginning and end of a track (i.e. time between sunrise/ sunset at the bird's start location and sunset/sunrise at the bird's end location). During predominantly daytime flights, an increase in available daylight did not influence distances traveled (a), but there was a statistically significant effect during predominantly nighttime flights (b). These results indicate that some of the flight attributed to nighttime likely occurs during daylight hours.

\section{Acknowledgements}

For field assistance, we thank James Mejeur, Anne Savage, Lauren Moscar, Mackenzie Pearson, Maryse Gagné, Ashley Pidwerbesky, Evelien de Greef, Paul and Maxine Clifton, Susan Ray, students from West Texas A\&M University and Texas Tech University, and volunteers. Funding provided by the University of Manitoba, Natural Sciences and Engineering Research Council of Canada, Disney Conservation Fund, Purple Martin Conservation Association, U.S. Department of Energy/National Nuclear Security Administration in cooperation with Consolidated Nuclear Security, LLC. Research protocols comply with Guidelines to The Use of Wild Birds in Research and were approved by the Canadian Council on Animal Care (F14009-1-2-3).

\section{Authors' contributions}

$\mathrm{CDL}, \mathrm{SBA}$, and KCF conceived the project and designed the study, all authors conducted fieldwork, CDL, SBA, and AMK analyzed the data, CDL, AMK, and KCF drafted the manuscript, all authors contributed to editing the manuscript. The author(s) read and approved the final manuscript.

\section{Funding}

Research was supported by the University of Manitoba, Natural Sciences and Engineering Research Council's Discovery Grant Program, Disney

Conservation Fund, Purple Martin Conservation Association, U.S. Department of Energy/National Nuclear Security Administration in cooperation with Consolidated Nuclear Security, LLC.

Availability of data and materials

Data will be made publicly available.

\section{Declarations}

Ethics approval and consent to participate

This research was conducted with approval from Animal Care Committees.

Consent for publication

All authors consent to publication.

\section{Competing interests}

No competing interests to declare.

\section{Author details}

'Department of Biological Sciences, University of Manitoba, Winnipeg, MB, Canada. ${ }^{2}$ Consolidated Nuclear Security, LLC, Pantex Plant, Amarillo, TX 79120, USA. ${ }^{3}$ Disney's Animals, Science, and Environment, Lake Buena Vista, FL 32830, USA. ${ }^{4}$ Purple Martin Conservation Association, Erie, PA, USA.

Received: 14 December 2020 Accepted: 30 March 2021

Published online: 26 April 2021

\section{References}

1. Newton I. The migration ecology of birds. London: Acad. Press; 2008.

2. Kerlinger $P$, Moore FR. Atmospheric structure and avian migration. Curr Ornithol. 1989;6:109-42.

3. Adamík P, Emmenegger T, Briedis M, Gustafsson L, Henshaw I, Krist M, et al. Barrier crossing in small avian migrants: individual tracking reveals prolonged nocturnal flights into the day as a common migratory strategy. Sci Rep. 2016;6(1):21560. https://doi.org/10.1038/srep21560.

4. Alerstam T. Flight by night or day? Optimal daily timing of bird migration. J Theor Biol. 2009;258(4):530-6. https://doi.org/10.1016/j.jtbi.2009.01.020.

5. Jiguet F, Burgess M, Thorup K, Conway G, Arroyo Matos JL, Barber L, et al. Desert crossing strategies of migrant songbirds vary between and within 
species. Sci Rep. 2019;9(1):20248. https://doi.org/10.1038/s41598-01956677-4.

6. Evens R, Conway GJ, Henderson IG, Cresswell B, Jiguet F, Moussy C, et al. Migratory pathways, stopover zones and wintering destinations of Western European nightjars Caprimulgus europaeus. Ibis. 2017;159(3):680-6. https:// doi.org/10.1111/ibi.12469.

7. Korpach AM, Mills A, Heidenreich C, Davy CM, Fraser KC. Blinded by the light? Circadian partitioning of migratory flights in a nightjar species. J Ornithol. 2019;160(3):835-40. https://doi.org/10.1007/s10336-019-01668-5.

8. Nilsson C, BBackman J, Karlsson H, Alerstam T. Timing of nocturnal passerine migration in Arctic light conditions. Polar Biol. 2015;38(9):1453-9. https://doi. org/10.1007/s00300-015-1708-x.

9. Alerstam T. Bird migration. Cambridge: Cambridge University Press; 1990.

10. Strandberg R, Alerstam $T$. The strategy of fly-and-forage migration, illustrated for the osprey (Pandion haliaetus). Behav Ecol Sociobiol. 2007; 61(12):1865-75. https://doi.org/10.1007/s00265-007-0426-y.

11. Hadjikyriakou TG, Nwankwo EC, Virani MZ, Kirschel ANG. Habitat availability influences migration speed, refueling patterns and seasonal flyways of a flyand-forage migrant. Mov Ecol. 2020;8:1-14.

12. Imlay TL, Taylor PD. Diurnal and crepuscular activity during fall migration for four species of aerial foragers. Wilson J Ornithol. 2020;132(1):159-64. https:// doi.org/10.1676/1559-4491-132.1.159.

13. Fraser KC, Silverio C, Kramer P, Mickle N, Aeppli R, Stutchbury BJM. A transhemispheric migratory songbird does not advance spring schedules or increase migration rate in response to record-setting temperatures at breeding sites. PLoS One. 2013;8(5):e64587. https://doi.org/10.1371/journal. pone.0064587.

14. Fraser KC, Stutchbury BJM, Kramer P, Silverio C, Barrow J, Newstead D, et al. Consistent range-wide pattern in fall migration strategy of purple Martin (Progne subis), despite different migration routes at the Gulf of Mexico. Auk. 2013;130(2):291-6. https://doi.org/10.1525/auk.2013.12225.

15. Blackburn E, Burgess M, Freeman B, Risely A, Izang A, Ivande S, et al. Spring migration strategies of whinchat Saxicola rubetra when successfully crossing potential barriers of the Sahara and the Mediterranean Sea. Ibis. 2018;161:131-46.

16. Brown CR, Tarof S. Purple Martin (Progne subis), version 1.0. In Birds of the World (A.F.Poole, Editor). Ithaca: Cornell Lab Ornithol; 2020.

17. Rappole JH, Tipton AR. New harness design for attachment of radio transmitters to small passerines. J F Ornithol. 1991;62:335-7.

18. Google Earth. US Dept of State Geographer. 2021 Google.

19. Hijmans R, Vennes C. Geosphere: spherical trigonometry. 2014. R package version 1.3-11. https://mran.microsoft.com/snapshot/2014-10-02/web/packa ges/geosphere/index.html

20. Thieurmel B, Elmarhraoui A. Suncalc: compute sun position, sunlight phases, moon position and lunar phase. 2019. R package version 0.5.0. https://CRAN. R-project.org/package=suncalc

21. Kemp M, van Loon E, Shamoun-Baranes J, Bouten W. RNCEP: global weather and climate data at your fingertips. Methods Ecol Evol. 2011;3:6570. ISSN 2041-210X, doi: https://doi.org/10.1111/j.2041-210X.2011.00138.x, R package version 1.0.10

22. Kalnay, et al. The NCEP/NCAR 40-year reanalysis project. Bull Amer Meteor Soc. 1996;77:437-70.

23. Kanamitsu M, Ebisuzaki W, Woollen J, Yang S-K, Hnilo JJ, Fiorino M, et al. NCEP-DOE AMIP-II Reanalysis (R-2). Bull Am Meteorol Soc. 2002;83(11):163143 https://doi-org.uml.idm.oclc.org/10.1175/BAMS-83-11-1631.

24. Fernández-López J, Schliep K. rWind: download, edit and include wind data in ecological and evolutionary analysis. Ecography. 2019;42(4):804-10. https://doi.org/10.1111/ecog.03730.

25. Seers B. Clifro. 2020. R package version v3.2-3. https://cran.r-project.org/ web/packages/clifro/index.html

26. R Core Team. R: A language and environment for statistical computing. $R$ Foundation for Statistical Computing, Vienna, Austria. 2019. Available from: https://www.r-project.org/

27. Bürkner P-C. brms: An R Package for Bayesian Multilevel Models Using Stan. J Stat Softw. 2017;80(1):1-28. https://doi.org/10.18637/jss.V080.i01.

28. Gelman A, Goodrich B, Gabry J, Vehtari A. R-squared for Bayesian regression models. Am Stat. 2018;73(3):1-6. https://doi.org/10.1080/00031305.2018.154 9100.

29. ESRI. ArcGIS desktop: release 10. Redlands: Environmental Systems Research Institute; 2011.
30. Fraser KC, Shave A, Savage A, Ritchie A, Bell K, Siegrist J, et al. Determining fine-scale migratory connectivity and habitat selection for a migratory songbird by using new GPS technology. J Avian Biol. 2017;48:001-7.

31. Fraser KC, Stutchbury BJM, Silverio C, Kramer PM, Barrow J, Newstead D, et al. Continent-wide tracking to determine migratory connectivity and tropical habitat associations of a declining aerial insectivore. Proc Roy Soc B. 2012;279(1749):4901-6. https://doi.org/10.1098/rspb.2012.2207.

32. Briedis M, Beran V, Adamík P, Hahn S. Integrating light-level geolocation with activity tracking reveals unexpected nocturnal migration patterns of the tawny pipit. J Avian Biol. 2020;51(9). https://onlinelibrary-wiley-com.uml. idm.oclc.org/doi/10.1111/jav.02546.

33. Coppack T, Becker SF, Becker PJJ. Circadian flight schedules in nightmigrating birds caught on migration. Biol Lett. 2008;4(6):619-22. https://doi. org/10.1098/rsbl.2008.0388.

34. Ouwehand J, Both C. Alternate non-stop migration strategies of pied flycatchers to cross the Sahara desert. Biol Lett. 2016;12(4):20151060. https:// doi.org/10.1098/rsbl.2015.1060

35. Imlay TL, Saldanha S, Taylor PD. The fall migratory movements of Bank swallows, Riparia riparia: fly- and-forage migration? Avian Conserv Ecol. 2020;15(1):2. https://doi.org/10.5751/ACE-01463-150102.

36. Alerstam T. Optimal bird migration revisited. J Ornithol. 2011;152:S5-23.

37. Alerstam T. Detours in bird migration. J Theor Biol. 2001;209(3):319-31. https://doi.org/10.1006/jtbi.2001.2266.

38. Alerstam T, Chapman JW, Bäckman J, Smith AD, Karlsson H, Nilsson C, et al. Convergent patterns of long-distance nocturnal migration in noctuid moths and passerine birds. Proc Roy Soc B. 2011;278(1721):3074-80. https://doi. org/10.1098/rspb.2011.0058.

\section{Publisher's Note}

Springer Nature remains neutral with regard to jurisdictional claims in published maps and institutional affiliations.

\section{Ready to submit your research? Choose BMC and benefit from:}

- fast, convenient online submission

- thorough peer review by experienced researchers in your field

- rapid publication on acceptance

- support for research data, including large and complex data types

- gold Open Access which fosters wider collaboration and increased citations

- maximum visibility for your research: over $100 \mathrm{M}$ website views per year

At BMC, research is always in progress.

Learn more biomedcentral.com/submissions 